Research Article

\title{
DFT Study and Antiparasitic Activity of Some Azo Dyes Containing Uracil
}

\author{
Nevin Süleymanoğlu (D), ${ }^{1}$ Pınar Kubaşık $\mathbb{D D}^{2}$ and Şahin Direkel $\mathbb{D D}^{3}$ \\ ${ }^{1}$ Vocational School of Technical Sciences, Gazi University, 06374 Ostim, Ankara, Turkey \\ ${ }^{2}$ Graduate School of Natural and Applied Sciences, Advanced Technologies, Gazi University, 06500 Ankara, Turkey \\ ${ }^{3}$ Department of Medical Microbiology, Faculty of Medicine, Giresun University, 28100 Giresun, Turkey
}

Correspondence should be addressed to Nevin Süleymanoğlu; nevinseylan@gmail.com

Received 12 April 2021; Accepted 27 July 2021; Published 4 August 2021

Academic Editor: Takayuki Ebata

Copyright ( $\odot 2021$ Nevin Süleymanoğlu et al. This is an open access article distributed under the Creative Commons Attribution License, which permits unrestricted use, distribution, and reproduction in any medium, provided the original work is properly cited.

\begin{abstract}
In this study, for the first time, molecular modeling and antiparasitic activity studies were carried out on some azo dyes containing uracil, 6-amino-5-[(4-nitrophenyl) diazenyl] pyrimidine-2,4 $(1 \mathrm{H}, 3 \mathrm{H})$-dione (dye I) and 6-amino-5-[(4-bromophenyl) diazenyl] pyrimidin-2,4 $(1 \mathrm{H}, 3 \mathrm{H})$-dione (dye II), which were resynthesized using the same method in the literature and whose molecular structures were confirmed using FTIR and ${ }^{1} \mathrm{H}-\mathrm{NMR}$ methods. In molecular modeling study, all calculations were performed using $\mathrm{DFT} / \mathrm{B} 3 \mathrm{LYP} / 6-311++\mathrm{G}(\mathrm{d}, \mathrm{p})$ method. The molecular structures of the possible tautomeric forms of dyes I and II were optimized, and their molecular total energies were calculated in the gas phase and DMSO solvent. IR and ${ }^{1} \mathrm{H}-\mathrm{NMR}$ spectral data of the possible tautomeric forms of dyes were obtained, and theoretical spectral data were compared with experimental ones. The evaluations show that, for both dyes, the spectral data of the imine-diketo-hydrazone form, which has the lowest energy and is hence determined to be the most stable form, are in agreement with the experimental ones. In antiparasitic activity study, dyes I and II were tested for the first time against parasites Leishmania infantum, Leishmania major, Leishmania tropica promastigotes, and Trichomonas vaginalis trophozoites. In vitro antileishmanial activities against Leishmania promastigotes were tested by microdilution broth assay with Alamar Blue in RPMI 1640 medium, and in vitro trichomonacidal activities against Trichomonas vaginalis parasite were tested using TYM medium. In tests, antileishmanial and trichomonacidal effects were determined by comparing the obtained minimum inhibitory concentration (MIC) and minimum lethal concentration (MLC) values with those obtained for standard drugs (amphotericin B and metronidazole, respectively).
\end{abstract}

\section{Introduction}

Azo dyes are important colorants with chromosome azo group $(-\mathrm{N}=\mathrm{N}-)$. Due to their special chemical and biological properties, they have potential applications in medicine and pharmacology, such as antibacterial, antifungal, antitumor, and antioxidant activities [1-3]. In addition, they are easy to use and offer strong colors in textile applications as well as being relatively inexpensive. With these aspects, azo dyes attracted considerable attention in scientific studies $[4,5]$. Uracil derivatives belonging to the pyrimidines group, which have an important role in the binding of ribosomes and phosphate in the synthesis of enzymes required in basic biological processes, show important pharmacological activities $[6,7]$. Studies on synthetic pyrimidines reveal the presence of remarkable biological and pharmacological properties [8]. Therefore, uracil derivatives are used in drugs with antitumor, antibacterial, and antiviral properties [7].

Leishmaniasis is a disease caused by Leishmania parasites and transmitted by the bites of some sandflies, which differs clinically and epidemiologically, and is an important health problem worldwide $[9,10]$. Visceral leishmaniasis (VL, Kala-Azar), cutaneous leishmaniasis (CL, Oriental Boil), and mucocutaneous leishmaniasis (MCL) are three different clinical forms of leishmaniasis [11]. In the Mediterranean basin, types of Leishmania causing leishmaniasis are as follows: generally Leishmania infantum (L. infantum) for VL and Leishmania major (L. major) and Leishmania 
tropica (L. tropica) for CL [12]. About 1 billion people are at risk in five continents, and it is estimated that the number of new patients every year is 30000 for VL and 1 million for CL [13]. The treatment alternatives of the disease are limited, and many of the drugs used are expensive and have side effects that cause significant health problems. Therefore, in recent years, many studies have been carried out to develop a drug that is cheap and safe and has a very low side effect, and antileishmanial tests have been applied on a variety of natural and synthetic compounds [14-17].

Trichomonas vaginalis (T. vaginalis) is a protozoan parasite with flagellates and only human host, found in trophozoite form [18]. It causes infection in the urogenital system of both women and men. Trichomoniasis causes vaginitis, cervicitis, and urethritis, especially in women [19]. 5-Nitroimidazole derivatives (metronidazole, ornidazole, and tinidazole) are currently used in the treatment of trichomoniasis, and these drugs cause DNA damage and cause cell death of the parasite. Although metronidazole is the first choice drug, it has mutagenic and carcinogenic effects. Therefore, alternative treatment methods in the treatment of trichomoniasis are being investigated [20].

In this study, in order to contribute to pharmacological studies, it was aimed to investigate azo dyes containing uracil, which have remarkable pharmacological properties but have not been previously tested for antiparasitic activity. For this reason, some azo dyes given in literature were resynthesized by the same method, and their structures were confirmed by FTIR and ${ }^{1}$ H-NMR methods. For the first time, theoretical study and antiparasitic activity study were carried out on the azo dyes containing uracil called as 6-amino-5-[(4-nitrophenyl) diazenyl] pyrimidine-2,4 $(1 \mathrm{H}, 3 \mathrm{H})$-dione (dye I) and 6-amino-5-[(4-bromophenyl) diazenyl] pyrimidin-2,4 $(1 \mathrm{H}, 3 \mathrm{H})$-dione (dye II). In the theoretical study, the molecular structures of the possible tautomeric forms of dyes I and II were optimized, and the structural and some spectral parameters of dyes were determined by density functional theory (DFT) method with $6-311++\mathrm{G}(\mathrm{d}, \mathrm{p})$ basis set. Theoretical IR and ${ }^{1} \mathrm{H}$-NMR data of the possible tautomeric forms of dyes I and II were compared with experimental ones. Thus, molecular structures of dyes I and II were firstly investigated by DFT methods. In vitro antileishmanial and trichomonacidal activities of these dyes were tested for the first time against parasites L. infantum, L. major, L. tropica, and $T$. vaginalis, respectively. In vitro antileishmanial activities were tested by microdilution broth assay with Alamar Blue in Roswell Park Memorial Institute (RPMI) 1640 medium, and in vitro trichomonacidal activity was tested using Trypticase Yeast extract Maltose (TYM) medium. As standard control drugs, amphotericin B for Leishmania and metronidazole for Trichomonas were used. Investigation of in vitro antileishmanial and trichomonacidal activities of azo dyes containing uracil, dyes I and II, can make an important contribution to drug design and development studies and can guide the determination of chemicals to be considered in these studies in terms of increasing the variety of compounds that can be used in pharmacological research.

\section{Experimental and Computational Method}

2.1. Instrumentation. ${ }^{1} \mathrm{H}-\mathrm{NMR}$ spectra of dyes I and II were recorded on a Varian-Mercury $400 \mathrm{MHz}$ spectrometer. These measurements used TMS as an internal standard and DMSO- $d_{6}$ as solvent. The FTIR spectra of dyes I and II were recorded on a Perkin-Elmer Spectrum One Fourier-transform IR spectrometer (resolution 4) in $\mathrm{KBr}$ pellets.

2.2. Synthesis. In this study, azo dyes containing uracil given in the literature, dye I and dye II, were resynthesized by the same method $[21,22]$. The synthesis reaction of azo dyes containing uracil is shown in Scheme 1. N,N-Dimethylaniline, $\mathrm{KOH}$, 4-bromine, concentrated $\mathrm{HCl}$ acid, $\mathrm{NaNO}_{2}$, and 6-amino uracil used for the synthesis of dyes I and II were purchased from MERCK and used without further purification. Pure water was obtained in the laboratory.

2.3. Computational Procedures. Gaussian09 [23] program was used to obtain the optimized structures, IR vibration frequencies, and ${ }^{1} \mathrm{H}-\mathrm{NMR}$ chemical shifts of azo dyes containing uracil by using DFT/B3LYP $[24,25]$ method and $6-311++G(d, p)$ basis set. The geometries were visualized by GaussView 5.0 [26] software package. The calculated vibration frequencies were scaled with scale factors 0.983 and 0.958 applied to frequencies smaller than $1700 \mathrm{~cm}^{-1}$ and greater than $1700 \mathrm{~cm}^{-1}$, respectively $[27,28]$. By GIAO method, ${ }^{1} \mathrm{H}$-NMR chemical shift values in DMSO solvent of dyes I and II were calculated at B3LYP/6-311++G(d,p) level $[29,30]$. Chemical shift values were scaled by scale factor of 31.9681 ppm [31, 32].

2.4. In Vitro Antiparasitic Activity. The antiparasitic properties of dyes I and II were determined by testing their antileishmanial and trichomonacidal activities against $L$. infantum, L. tropica, L. major promastigotes, and T. vaginalis trophozoites, respectively. The study was carried out in vitro using microdilution broth assay. The results of antileishmanial activity against Leishmania promastigotes and trichomonacidal activity against $T$. vaginalis were evaluated by taking into account minimum inhibitory concentration (MIC) and minimum lethal concentration (MLC) values, respectively.

2.4.1. Antileishmanial Activity. The axenic standard $L$. infantum, $L$. tropica, and $L$. major promastigotes were used in the study. The promastigotes were propagated on RPMI-1640 medium and maintained by passaging [33, 34]. Promastigotes were washed with phosphate buffered saline (PBS). Each of azo dyes containing uracil was dissolved in $\mathrm{DMSO} / \mathrm{H}_{2} \mathrm{O}(10 \%)$ and sterilized by membrane filter with a diameter of $0.45 \mu \mathrm{m}$. Final concentrations were prepared by adding RPMI-1640 medium. The stock solution was diluted in 96-well microplates, and $2.5 \times 10^{7}$ cells $/ \mathrm{mL}$ Leishmania promastigotes were added onto the wells. After incubating the microplates at $27^{\circ} \mathrm{C}$ for 20 hours in the incubator, Alamar Blue was added to the wells and incubated again at $27^{\circ} \mathrm{C}$ for 4 
hours. Microplates were evaluated at 24, 48, and 72 hours, and the results were recorded. In the study, amphotericin B was used as a control drug, and all tests were repeated twice. As expected, the color will change from blue to pink in the positive control well and no color change was observed in the negative control well $[35,36]$.

2.4.2. Trichomonacidal Activity. T. vaginalis was produced in TYM medium. $1 \mathrm{~mL}$ inactivated human serum was added onto the medium under sterile conditions. Penicillin, streptomycin, and triflux were added under sterile conditions and then incubated in a $37^{\circ} \mathrm{C}$ incubator. Two days later, whether there was reproduction was observed. To test the viability of the trophozoites, $0.4 \%$ trypan blue was used and counted in the hemocytometer slide [37].

Azo dyes containing uracil, dyes I and II, were prepared in concentrations of $32,16,8,4,2$, and $1 \mathrm{mg} / \mathrm{mL}$ in saline and distributed into sterile Eppendorf tubes. T. vaginalis were incubated at room temperature with $5 \times 10^{6}$ trophozoites/ $\mathrm{mL}$. The viability of the parasites was checked at specific times and noted. Recontrol seedlings were performed from the tubes in which the live cells were not detected, and the reproduction was evaluated. Parasites not added to dyes I and II were kept in the same environment as control [38].

\section{Results and Discussion}

3.1. Optimized Geometries. In theoretical study of azo dyes containing uracil called 6-amino-5-[(4-nitrophenyl) diazenyl] pyrimidine-2,4 $(1 \mathrm{H}, 3 \mathrm{H})$-dione (dye I) and 6-amino5-[(4-bromophenyl) diazenyl] pyrimidin-2,4 $(1 \mathrm{H}, 3 \mathrm{H})$ dione (dye II), firstly, the molecular structures of dyes I and II in possible tautomeric forms given in Scheme 2 were optimized by DFT/B3LYP/6-311++G(d,p) method in the gas phase and in DMSO solvent, and their molecular total energies, in $\mathrm{kcal} / \mathrm{mol}$, were calculated. The most stable forms for dyes I and II in gas phase and in DMSO solvent are the imine-diketo hydrazone forms with the lowest energy. As in the gas phase/in DMSO solvent, molecular total energies of the imine-diketo hydrazone forms are obtained as $-637226.06 /-637240.19 \mathrm{kcal} / \mathrm{mol}$ for dye I and as $-2123760.46 /-2123771.10 \mathrm{kcal} / \mathrm{mol}$ for dye II, respectively. The optimized molecular structures of dyes I and II in iminediketo-hydrazone forms are shown in Figure 1, and their structural parameters are presented in Table 1 .

The structural parameters obtained by geometry optimization were compared with those obtained from X-ray method for similar single-crystalline compounds given in the literature; thus, the suitability of the method used and that of the selected basis set were discussed.

As can be seen from Table 1, the $\mathrm{C}=\mathrm{O}$ bond lengths in the uracil rings of dyes I and II were calculated as 1.209,1.231/ $1.211,1.232 \AA$ for the imine-diketo-hydrazone forms, respectively. In the literature, this length is between 1.2042 (19) and $1.2143(19) \AA[39,40]$. The $\mathrm{C} 1-\mathrm{N} 17$ and $\mathrm{C} 1-\mathrm{N} 18$ bond lengths were calculated as $1.373-1.403 / 1.373-1.401 \AA$, respectively. In literature, this length is 1.373 (2) and 1.376 (2) $\AA$ [22]. The $\mathrm{N} 17-\mathrm{C} 1-\mathrm{N} 18$ bond angles in the uracil rings of dyes I and II were calculated as $114.3 / 114.3^{\circ}$ for the iminediketo-hydrazone forms, respectively. In the literature, this angle was given as $117.11(14)^{\circ}$ [41]. The C10-C5-N15-N16 torsion angle was calculated as $180.0 / 179.9^{\circ}$ for the iminediketo-hydrazone forms of dyes I and II, respectively. In the literature, this angle is given as $177.8(3)^{\circ}$ [42].

Since dyes I and II have values compatible with the structural parameters of similar single crystalline compounds in the literature, it can be concluded that the appropriate method and basis set were chosen. This is also an indication that spectral parameters can also be determined correctly.

3.2. Vibrational Spectra and ${ }^{1} H-N M R$ Spectra. The IR and ${ }^{1} \mathrm{H}-\mathrm{NMR}$ calculations of dyes I and II were carried out at DFT/B3LYP/6-311++G(d,p) level by considering the possible tautomeric forms to T-VIII from T-I (Scheme 2). Theoretical IR and ${ }^{1} \mathrm{H}-\mathrm{NMR}$ data were compared with experimental data, and the compatibility of theoretically obtained values for dyes I and II with experimental data was discussed.

Considering Scheme 2, for T-I, $\mathrm{NH}_{2}, \mathrm{C} 1=\mathrm{O} / \mathrm{C} 4=\mathrm{O}$, and $\mathrm{N}=\mathrm{N}$ stretching bands are calculated as $3535_{\text {as }} / 3405_{\mathrm{s}} \mathrm{cm}^{-1}$, $1733 / 1696 \mathrm{~cm}^{-1}$, and $1468 \mathrm{~cm}^{-1}$ for dye I and as $3530_{\text {as }} / 3405_{\mathrm{s}}$ $\mathrm{cm}^{-1}, 1728 / 1692 \mathrm{~cm}^{-1}$, and $1493 \mathrm{~cm}^{-1}$ for dye II. For T-II, $\mathrm{NH}_{2}, \mathrm{C} 1=\mathrm{O} / \mathrm{C} 4 \mathrm{O}-\mathrm{H}$, and $\mathrm{N}=\mathrm{N}$ stretching bands are calculated as $3561_{\mathrm{as}} / 3439_{\mathrm{s}} \mathrm{cm}^{-1}, 1713 / 3012 \mathrm{~cm}^{-1}$, and $1408 \mathrm{~cm}^{-1}$ for dye I and as $3558_{\mathrm{as}} / 3435_{\mathrm{s}} \mathrm{cm}^{-1}, 1707 /$ $3007 \mathrm{~cm}^{-1}$, and $1488 \mathrm{~cm}^{-1}$ for dye II. For T-III, $\mathrm{NH}_{2}$, $\mathrm{C} 1 \mathrm{O}-\mathrm{H} / \mathrm{C} 4=\mathrm{O}$, and $\mathrm{N}=\mathrm{N}$ stretching bands are calculated as $3573_{\text {as }} / 3440_{\mathrm{s}} \mathrm{cm}^{-1}, 3620 / 1695 \mathrm{~cm}^{-1}$, and $1438 \mathrm{~cm}^{-1}$ for dye I and as $3578_{\mathrm{as}} / 3443_{\mathrm{s}} \mathrm{cm}^{-1}, 3622 / 1691 \mathrm{~cm}^{-1}$, and $1504 \mathrm{~cm}^{-1}$ for dye II. For T-IV, $\mathrm{NH}_{2}, \mathrm{C} 1 \mathrm{O}-\mathrm{H} / \mathrm{C} 4 \mathrm{O}-\mathrm{H}$, and $\mathrm{N}=\mathrm{N}$ stretching bands are calculated as $3581_{\text {as }} / 3453_{\mathrm{s}} \mathrm{cm}^{-1}, 3627 /$ $2969 \mathrm{~cm}^{-1}$, and $1439 \mathrm{~cm}^{-1}$ for dye I and as $3584_{\mathrm{as}} / 3456_{\mathrm{s}}$ $\mathrm{cm}^{-1}, 3630 / 2973 \mathrm{~cm}^{-1}$, and $1440 \mathrm{~cm}^{-1}$ for dye II.

Accordingly, since the $\mathrm{NH}_{2}$ and $\mathrm{CO}-\mathrm{H}$ bands given above are not observed in the FTIR spectra of dyes I and II given in Figure 2, the possible tautomeric forms to T-IV from T-I can be eliminated.

Similarly, the bands calculated as dye I/dye II are as follows: for T-VI, C4O-H bands at $3569 / 3571 \mathrm{~cm}^{-1}$, respectively; for T-VII, C1O-H band at $3614 / 3615 \mathrm{~cm}^{-1}$, respectively; for T-VIII, C1O-H and C4O-H bands at 3612/ $3615 \mathrm{~cm}^{-1}$ and $3568 / 3570 \mathrm{~cm}^{-1}$ which are absent in FTIR spectra of dyes I and II (Figure 2), and thus possible tautomeric forms to T-VIII from T-VI can be eliminated.

As a result, when the FTIR spectra of dyes I and II are compared with the theoretical ones, it can be said that, in the solid state, dyes I and II are in the imine-diketo-hydrazone form (T-V in Scheme 2). Some vibration bands are considered to confirm the molecular structures of dyes I and II, and theoretical ones obtained in the gas state for iminediketo-hydrazone forms are given in Table 2 .

As evaluated in Table 2, N17-H/N18-H stretching bands in the FTIR spectra of dyes I and II (Figures 2(a) and 2(b)) were observed at $3116 / 3116 \mathrm{~cm}^{-1}$ and $3144 / 3144 \mathrm{~cm}^{-1}$, respectively, and they were calculated as $3452 / 3444 \mathrm{~cm}^{-1}$ for 
<smiles>[R]c1ccc(/N=N/c2c(N)[nH]c(=O)[nH]c2=O)cc1</smiles>

Scheme 1: Synthesis path of azo dyes containing uracil: dye I $\left(\mathrm{R}=\mathrm{NO}_{2}\right)$ and dye II $(\mathrm{R}=\mathrm{Br})$.<smiles>[R]c1ccc(N=Nc2c(N)[nH]c(=O)[nH]c2=O)cc1</smiles><smiles>[R]c1ccc(/N=N/c2c(N)nc(=O)[nH]c2O)cc1</smiles><smiles>[R]c1ccc(N=Nc2c(N)nc(O)[nH]c2=O)cc1</smiles><smiles>[R]c1ccc(N=Nc2c(N)nc(O)nc2O)cc1</smiles><smiles>[R]c1ccc(NN=C2C(=N)NC(=O)NC2=O)cc1</smiles><smiles>[R]c1ccc(N/N=C2/C(=N)NC(=O)N=C2O)cc1</smiles><smiles>[R]c1ccc(N/N=C2/C(=N)N=C(O)NC2=O)cc1</smiles><smiles>[Al]=[W]</smiles><smiles>[R]c1ccc(NN=C2C(=N)N=C(O)N=C2O)cc1</smiles>

Scheme 2: Possible tautomeric forms of azo dyes containing uracil: dye I $\left(\mathrm{R}=\mathrm{NO}_{2}\right)$ and dye II $(\mathrm{R}=\mathrm{Br})$.

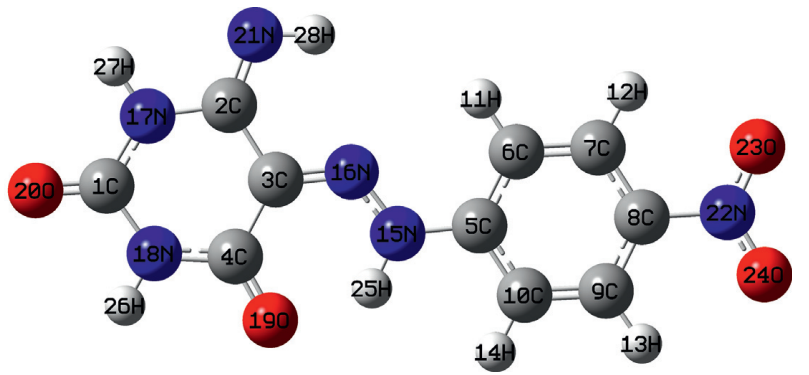

(a)

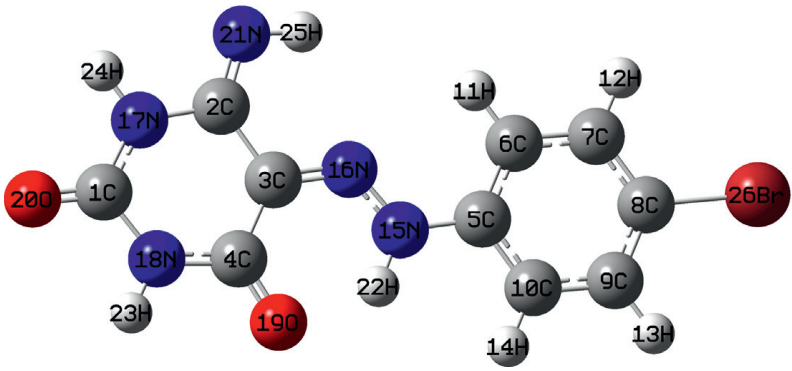

(b)

FIgURE 1: The molecular structures in the imine-diketo-hydrazone form of (a) dye I and (b) dye II.

dye I and $3455 / 3448 \mathrm{~cm}^{-1}$ for dye II. The $\mathrm{N} 21-\mathrm{H}$ imine band was observed as $3116 / 3099 \mathrm{~cm}^{-1}$ for dyes I/II and was calculated as $3369 / 3369 \mathrm{~cm}^{-1}$, respectively. N15-H hydrazone band calculated as $3198 / 3195 \mathrm{~cm}^{-1}$ for dyes I/II was observed at $3168 / 3216 \mathrm{~cm}^{-1}$. The experimental and calculated values of other stretching bands given in Table 2 are quite compatible.

As can be seen from Figure 1, the optimized molecular structures of dyes I and II were obtained in the most stable structure revealing the presence of N15-H...O19 type intramolecular hydrogen bonds. Therefore, deviations between experimental and calculated ones are small, and values obtained as $30 / 21 \mathrm{~cm}^{-1}$ for dyes $\mathrm{I} / \mathrm{II}$, respectively, can be considered compatible. As observed for N17-H/N18-N17 stretching bands and $\mathrm{N} 21-\mathrm{H}$ imine bands, the considerable deviations calculated as $336 / 328 \mathrm{~cm}^{-1}$ and $253 \mathrm{~cm}^{-1}$ for dye
I, $311 / 304 \mathrm{~cm}^{-1}$ and $270 \mathrm{~cm}^{-1}$ for dye II, respectively, can be explained by the presence of $\mathrm{N}-\mathrm{H}$... O type strong intermolecular hydrogen bonds.

${ }^{1} \mathrm{H}-\mathrm{NMR}$ spectra of dyes I and II were recorded in DMSO- $d_{6}$ (Figures 3(a) and 3(b)). For this reason, primarily the molecular structures of possible tautomeric forms of the dyes were optimized in DMSO solvent by DFT/B3LYP/6$311++\mathrm{G}(\mathrm{d}, \mathrm{p})$ method and, for all, ${ }^{1} \mathrm{H}-\mathrm{NMR}$ calculations in DMSO solvent were performed using DFT/B3LYP/6$311++\mathrm{G}(\mathrm{d}, \mathrm{p})$ method.

Considering Scheme 2, to T-IV from T-I and as dye I/dye II, $\mathrm{NH}_{2}$ proton signals are calculated as $5.03,5.20,5.32,5.33$ and $7.05,6.79,7.07,6.73 \mathrm{ppm} / 4.89,5.04,5.18,5.19$ and 6.94 , $6.64,6.95,6.59 \mathrm{ppm}$, respectively. These signals are not observed in ${ }^{1} \mathrm{H}$-NMR spectra of dyes I and II given in Figure 3. For this reason, possible tautomeric forms to T-IV 
TABLE 1: Some structural parameters obtained by DFT/B3LYP/6$311++G(d, p)$ method for imine-diketo-hydrazone (T-V) forms of dyes I and II.

\begin{tabular}{lccc}
\multicolumn{1}{c}{ Dye I } & \multicolumn{2}{c}{ Dye II } \\
\multicolumn{1}{c}{ Bond lengths $(\AA)$} & \multicolumn{2}{c}{ Bond lengths $(\AA)$} \\
\hline C1-O20 & 1.209 & C1-O20 & 1.211 \\
C1-N17 & 1.373 & C1-N17 & 1.373 \\
C1-N18 & 1.403 & C1-N18 & 1.401 \\
C2-N17 & 1.401 & C2-N17 & 1.402 \\
C2-N21 & 1.272 & C2-N21 & 1.273 \\
C4-N18 & 1.376 & C4-N18 & 1.379 \\
C4-O19 & 1.231 & C4-O19 & 1.232 \\
C2-C3 & 1.487 & C2-C3 & 1.483 \\
C3-C4 & 1.474 & C3-C4 & 1.468 \\
C3-N16 & 1.307 & C3-N16 & 1.311 \\
N15-N16 & 1.309 & N15-N16 & 1.303 \\
C5-N15 & 1.398 & C5-N15 & 1.405 \\
N22-O23 & 1.225 & C8-Br26 & 1.913 \\
N22-O24 & 1.225 & - & - \\
\hline \multicolumn{1}{c}{ Bond angles $\left(^{\circ}\right)$} & & Bond angles $\left(^{\circ}\right)$ \\
N17-C1-O20 & 124.2 & N17-C1-O20 & 124.1 \\
N18-C1-O20 & 121.5 & N18-C1-O20 & 121.6 \\
N17-C2-N21 & 117.8 & N17-C2-N21 & 117.6 \\
N17-C1-N18 & 114.3 & N17-C1-N18 & 114.3 \\
C3-C2-N21 & 127.8 & C3-C2-N21 & 128.0 \\
C2-C3-N16 & 116.3 & C2-C3-N16 & 116.2 \\
C3-N16-N15 & 121.4 & C3-N16-N15 & 121.5 \\
C5-N15-N16 & 121.6 & C5-N15-N16 & 121.8 \\
C6-C5-N15 & 122.2 & C6-C5- N15 & 122.3 \\
C3-C4-O19 & 123.3 & C3-C4-O19 & 123.5 \\
C7-C8-N22 & 119.3 & C7-C8-Br26 & 119.6 \\
O23-N22-O24 & 124.7 & - & - \\
\hline \multicolumn{1}{c}{ Torsion angles $\left({ }^{\circ}\right)$} & Torsion angles $\left({ }^{\circ}\right)$ \\
N18-C1-N17-C2 & -0.16 & N18-C1-N17-C2 & -0.1 \\
O20-C1-N17-C2 & 179.8 & O20-C1-N17-C2 & 179.9 \\
O20-C1-N18-C4 & 179.9 & O20-C1-N18-C4 & 179.9 \\
N17-C2-C3-C4 & -0.2 & N17-C2-C3-C4 & 0.0 \\
N21-C2-C3-N16 & -0.14 & N21-C2-C3-N16 & 0.0 \\
C4-C3-N16-N15 & 0.0 & C4-C3-N16-N15 & 0.0 \\
C2-C3-N16-N15 & 179.9 & C2-C3-N16-N15 & -179.9 \\
C6-C5-N15-N16 & 0.0 & C6-C5-N15-N16 & 0.0 \\
C6-C5-C10-C9 & 0.0 & C6-C5-C10-C9 & 0.0 \\
C10-C5-N15-N16 & 180.0 & C10-C5-N15-N16 & 179.9 \\
C5-C6-C7-C8 & 0.0 & C5-C6-C7-C8 & 0.0 \\
C7-C8-N22-O24 & -179.9 & C6-C7-C8-Br26 & -180.0 \\
\hline
\end{tabular}

from T-I can be eliminated. Similarly, $\mathrm{CO}-\mathrm{H}$ proton signals, as dye I/dye II, are obtained at $7.05 / 6.88 \mathrm{ppm}$ for T-VI, at $6.00 / 5.91 \mathrm{ppm}$ for T-VII, and 6.08 and $7.18 / 5.97$ and $7.02 \mathrm{ppm}$ for T-VIII which are absent in ${ }^{1} \mathrm{H}$-NMR spectra of dyes I and II. Therefore, T-VI, T-VII, and T-VIII are eliminated.

Thus, the ${ }^{1} \mathrm{H}$-NMR spectra of dyes I and II are consistent with the theoretical data of dyes I and II in the imine-diketohydrazone form (T-V). Theoretical ${ }^{1} \mathrm{H}-\mathrm{NMR}$ spectral data obtained for the imine-diketo-hydrazone form are given in Table 3 together with the experimental values.

As seen in Table 3, N15-H proton signals were observed at $14.03 / 14.02 \mathrm{ppm}$ for dyes I/II, respectively, and were calculated as $13.76 / 13.65 \mathrm{ppm}$. These results are consistent with the presence of $\mathrm{N} 15-\mathrm{H} \cdots \mathrm{O} 19$ type intramolecular hydrogen bonds shown by the optimized molecular structures of dyes I and II. N21-H, N17-H, and N18-H protons were observed at 11.06/10.80/10.89 ppm for dye I and 10.96/ $10.53 / 10.71 \mathrm{ppm}$ for dye II, respectively. The deviation of these values from the calculated chemical shift values is 2.18 / $3.58 / 3.75 \mathrm{ppm}$ for dye I and 2.36/3.37/3.68 ppm for dye II, respectively. Significant deviations of the experimental chemical shift values from the calculated values reveal the existence of $\mathrm{N}-\mathrm{H}$... O type intermolecular hydrogen bonds.

As evaluated in the FTIR and ${ }^{1} \mathrm{H}-\mathrm{NMR}$ experimental data (Figures 2 and 3) supporting each other of dyes I and II together with the theoretical data in Tables 2 and 3, the presence of strong intramolecular and intermolecular hydrogen bonds suggested for both dyes is consistent with the literature $[22,43]$.

\subsection{The Results of Antiparasitic Activity Test}

3.3.1. The Results of Antileishmanial Activity Test. Antileishmanial activities of dyes I and II against $L$. infantum, L. major, and L. tropica promastigotes were determined in vitro by microdilution broth assay with Alamar Blue, and MIC values were obtained. In the evaluation of antileishmanial activity, it is expected that Alamar Blue does not change color in the negative control. In addition, in promastigotes added as positive control, the blue color should turn pink, since inhibitory dye is added, and it is expected to continue vitality. In the case of negative and positive controls working, results can be evaluated. In other words, if the blue color does not change in the wells, the absence of vitality and turning pink determine that the vitality continues.

The results are shown in Figures 4-6. MIC values obtained in the tests are given in Table 4. According to the data obtained, it was determined that dye I was ineffective against all Leishmania species at the concentrations studied. Dye II was observed to be effective only against L. major promastigotes (MIC: $2500 \mu \mathrm{g} / \mathrm{mL}$ ), while it was found that it did not have antileishmanial activity against other Leishmania species. It was determined that amphotericin B, which is used as a control drug, is effective against all Leishmania species even the lowest concentration studied (MIC: $19 \mu \mathrm{g} / \mathrm{mL}$ ).

3.3.2. Trichomonacidal Activity Results. For trichomonacidal activities of dyes I and II against $T$. vaginalis trophozoites, MLC values were evaluated as in vitro with trypan blue of $0.5 \%$ at 16,24 , and 48 hours under invert microscope. For the lethal percent, formula 100 - (number of living cells/ total number of cells $\times 100$ ) was used. The MLC values obtained at the 16th, 24th, and 48th hours in the tests are given in Table 5. The microscopic images of the results of dyes I and II obtained against $T$. vaginalis trophozoites at the end of 48 hours are shown in Figures 7 and 8, respectively.

In in vitro trichomonacidal activity tests, at the initial evaluation at 16th hours, mobile $T$. vaginalis trophozoites were detected in all wells to which dyes I and II were added, including the positive control. At the second evaluation at 


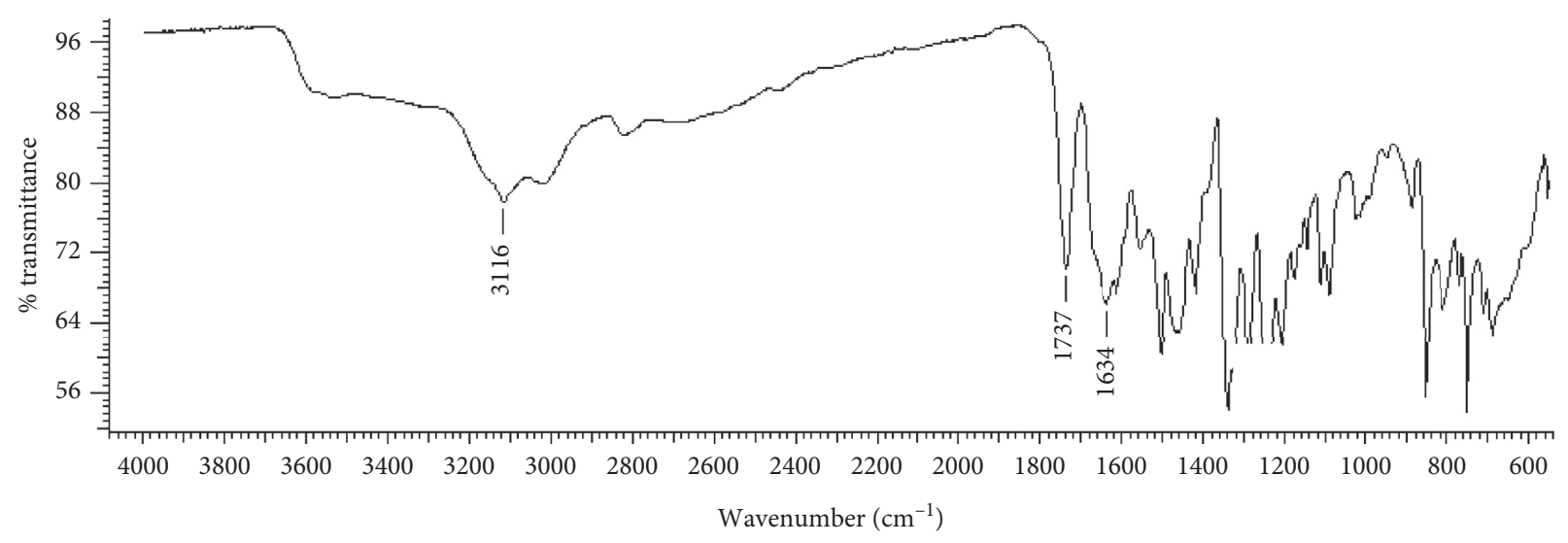

(a)

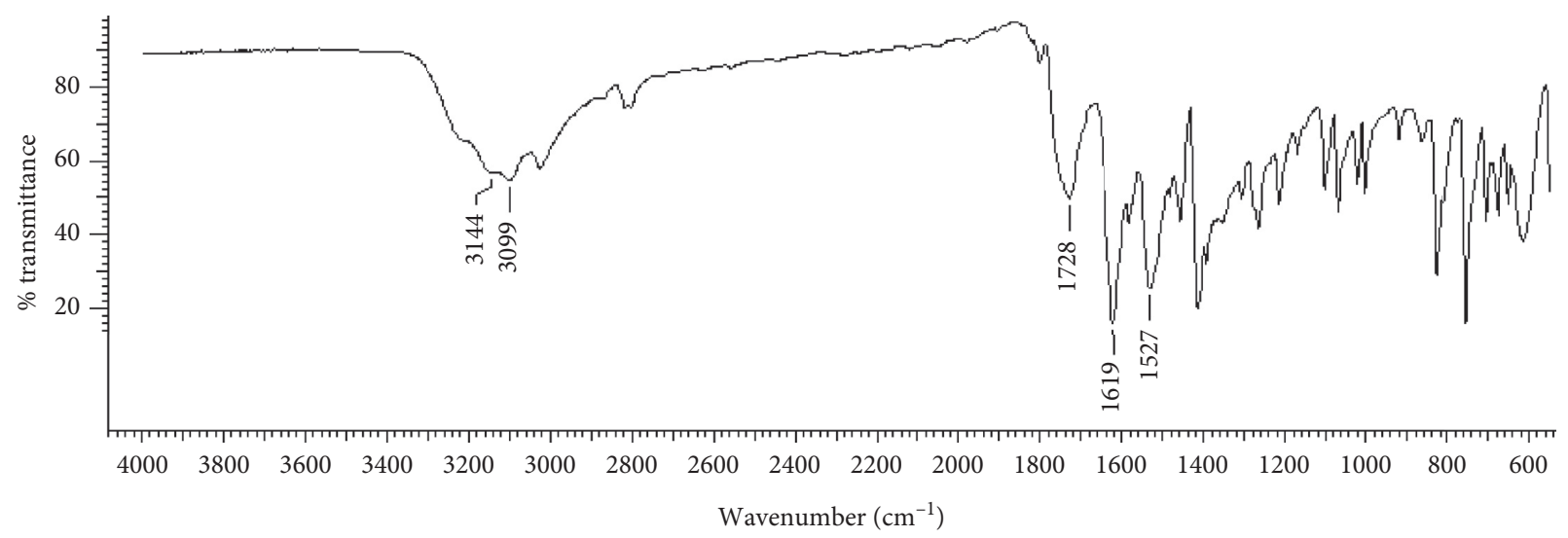

(b)

FIGURE 2: FTIR spectra of (a) dye I and (b) dye II.

TABLE 2: Some vibration frequencies $\left(\mathrm{cm}^{-1}\right)$ : experimental and calculated by DFT/B3LYP/6-311G++(d, p) for imine-diketo-hydrazone forms of dyes I and II.

\begin{tabular}{|c|c|c|c|c|}
\hline \multirow{2}{*}{ Assignments $^{\mathrm{a}}$} & \multicolumn{2}{|c|}{ Experimental $\left(\mathrm{cm}^{-1}\right)$} & \multicolumn{2}{|c|}{ Calculated $\left(\mathrm{cm}^{-1}\right)$} \\
\hline & Dye I & Dye II & Dye I & Dye II \\
\hline$v(\mathrm{~N} 17-\mathrm{H})$ & 3116 & 3144 & 3452 & 3455 \\
\hline$v(\mathrm{~N} 18-\mathrm{H})$ & 3116 & 3144 & 3444 & 3448 \\
\hline$\nu(\mathrm{N} 21-\mathrm{H})$ imine & $3116^{*}$ & $3099^{* *}$ & 3369 & 3369 \\
\hline$\nu(\mathrm{N} 15-\mathrm{H})$ hydrazone & $3116^{*}$ & $3144^{* * *}$ & 3198 & 3195 \\
\hline$\nu(\mathrm{C} 1=\mathrm{O} 20)$ & 1737 & 1728 & 1730 & 1724 \\
\hline$\nu(\mathrm{C} 4=\mathrm{O} 19)$ & 1634 & 1619 & 1650,1664 & 1643,1662 \\
\hline$\nu(\mathrm{C} 2=\mathrm{N} 21)$ & 1634 & 1619 & 1650,1664 & 1643,1662 \\
\hline$\nu(\mathrm{C}=\mathrm{C})$ & 1610 & 1619 & 1611 & 1600 \\
\hline$\nu(\mathrm{C} 3=\mathrm{N} 16)$ & $1552,1502,1458$ & 1580,1455 & $1561,1545,1472$ & 1554,1459 \\
\hline
\end{tabular}
$\mathrm{cm}^{-1}$, centered at $3144 \mathrm{~cm}^{-1}$

the end of the 24th hour, dyes I and II did not show any lethal effects. In the positive control, it was determined that the metronidazole used showed $75 \%, 59 \%, 43 \%, 25 \%$, and $10 \%$ lethal effects in other dilutions $(400,200,100$, and $50 \mu \mathrm{g} / \mathrm{mL})$ starting from the highest concentration $(800 \mu \mathrm{g} /$ $\mathrm{mL}$ ), respectively. In the 48th hour evaluation, it was determined that dye II had $79 \%$ lethal effect at $10,000 \mu \mathrm{g} / \mathrm{mL}$ dilution and $35 \%$ at $5000 \mu \mathrm{g} / \mathrm{mL}$ dilution.
It was determined that the concentration value of dye I, which has $100 \%$ lethal effect against $T$. vaginalis trophozoites in vitro, is $10,000 \mu \mathrm{g} / \mathrm{mL}$. At the end of test, the parasites in the well were taken into TYM medium again to determine whether there was growth at this concentration or not. Growth of the parasite was not detected in the medium, and $100 \%$ lethal effect was confirmed. In addition, it was determined that dye I was more effective than dye II and 


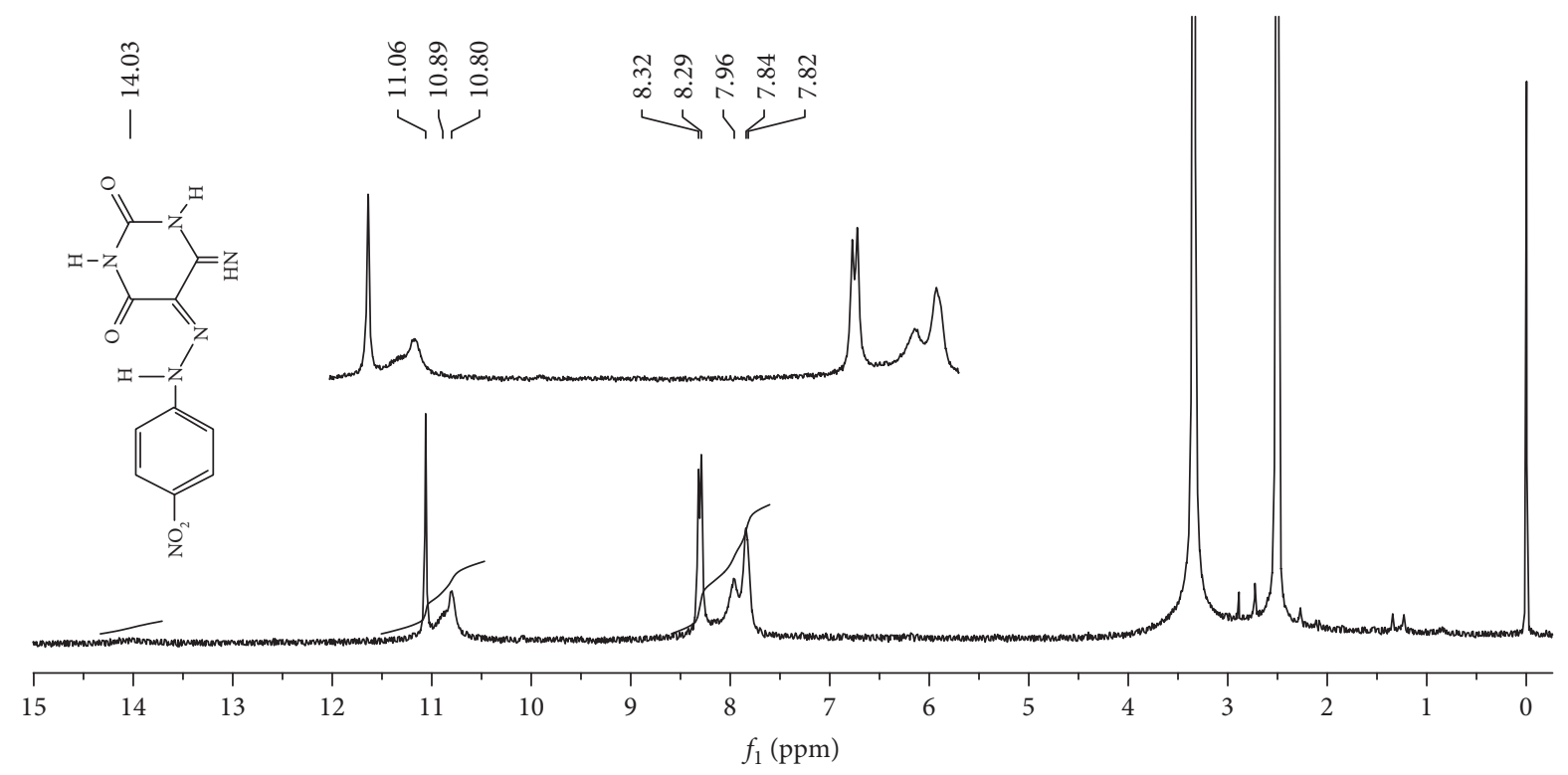

(a)
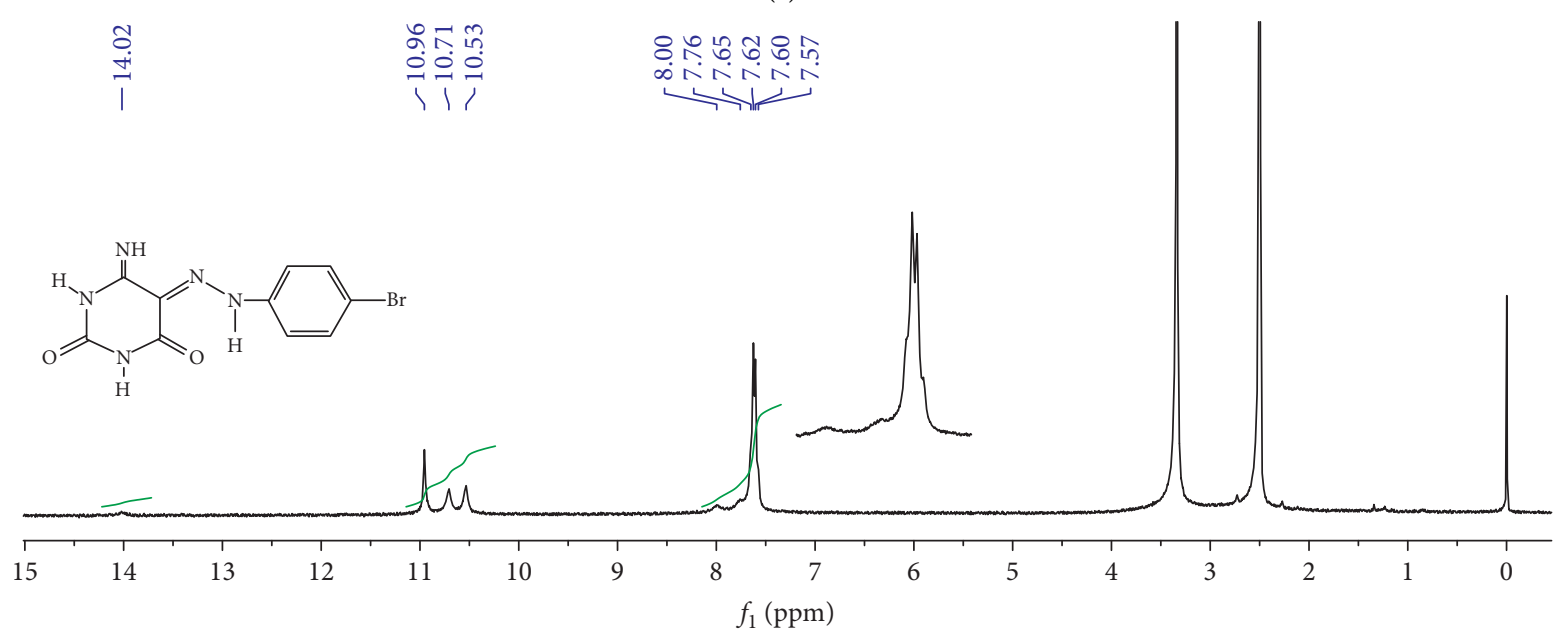

(b)

Figure 3: ${ }^{1} \mathrm{H}-\mathrm{NMR}$ spectra of (a) dye I and (b) dye II.

TABLE 3: ${ }^{1} \mathrm{H}$ isotropic chemical shifts of dyes I and II: experimental in DMSO- $d_{6}$ and for imine-diketo-hydrazone forms (T-V) calculated in DMSO by DFT/B3LYP/6-311++G(d,p) method (all values in ppm).

\begin{tabular}{lcccc}
\hline \multirow{2}{*}{ Atom } & \multicolumn{2}{c}{ Experimental } & \multicolumn{2}{c}{ Calculated } \\
& Dye I & Dye II & Dye I & 13.76 \\
N15-H & 14.03 & 14.02 & 8.88 & 8.22 \\
N21-H & 11.06 & 10.96 & 7.65 \\
N17-H & 10.80 & 10.53 & 7.14 & 7.16 \\
N18-H & 10.89 & 10.71 & 8.26 & 7.03 \\
H11 & $7.96-7.82$ & $7.60-7.57$ & 8.66 & 7.16 \\
H12 & $8.32-8.29$ & $7.62-7.60$ & 8.68 & 7.75 \\
H13 & $8.32-8.29$ & $7.62-7.60$ & 7.32 & 7.29 \\
H14 & $7.96-7.82$ & $7.60-7.57$ & & \\
\hline
\end{tabular}




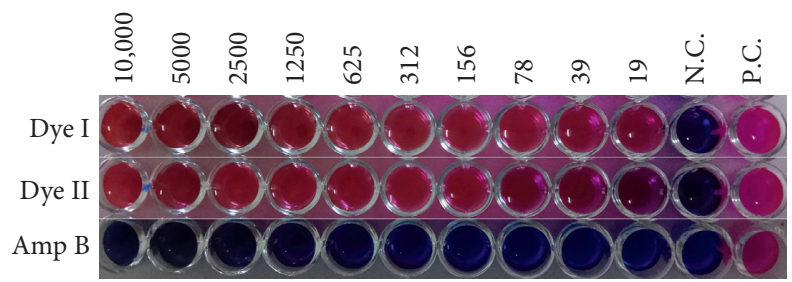

FIGURE 4: In vitro antileishmanial activity against Leishmania infantum promastigotes; dye I, dye II, control drug amphotericin B, and dilution concentrations 10000-19 $\mu \mathrm{g} / \mathrm{mL}$. NC: negative control and PC: positive control.

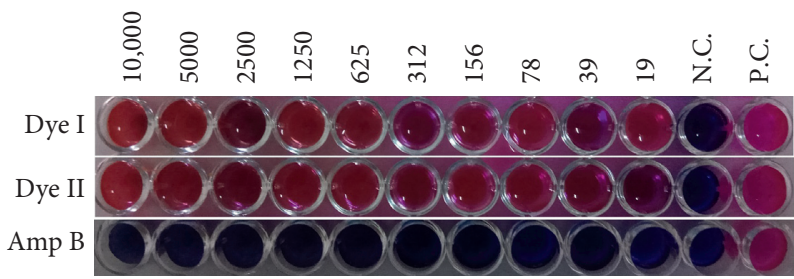

FIGURE 5: In vitro antileishmanial activity Leishmania tropica promastigotes; dye I, dye II, control drug amphotericin B, and dilution concentrations 10,000-19 $\mu \mathrm{g} / \mathrm{mL}$. NC: negative control and PC: positive control.

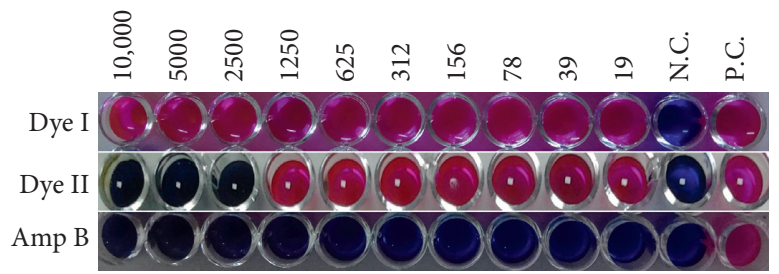

FIgURE 6: In vitro antileishmanial activity Leishmania major promastigotes; dye I, dye II, control drug amphotericin B, and dilution concentrations 10,000-19 $\mathrm{g} / \mathrm{mL}$. NC: negative control and PC: positive control.

TABLe 4: Minimum inhibitory concentration (MIC) values (in $\mu \mathrm{g} / \mathrm{mL}$ ) obtained against standard Leishmania promastigotes.

\begin{tabular}{lccc}
\hline Dyes & & MIC values $(\mu \mathrm{g} / \mathrm{mL})$ & L. major \\
\hline I & L. infantum & L. tropica & $>10,000$ \\
II & $>10,000$ & $>10,000$ & 2500 \\
Amphotericin B & $>10,000$ & $>10,000$ & $<19$ \\
\hline
\end{tabular}

TABLE 5: Minimum lethal concentration (MLC) values obtained at the end of 16, 24, and 48 hours against T. vaginalis trophozoites.

\begin{tabular}{|c|c|c|c|c|c|c|c|c|c|c|c|c|}
\hline \multirow{2}{*}{ Concentration $(\mu \mathrm{g} / \mathrm{mL})$} & \multicolumn{3}{|c|}{ 16th h } & \multicolumn{3}{|c|}{ 24th h } & \multicolumn{3}{|c|}{ 48th h } & \multirow{2}{*}{\multicolumn{3}{|c|}{$\begin{array}{l}\text { Metronidazole }(\mu \mathrm{g} / \mathrm{mL}) \\
\text { (positive control) }\end{array}$}} \\
\hline & Dye I & Dye II & Control & Dye I & Dye II & Control & Dye I & Dye II & Control & & & \\
\hline 10,000 & 0 & 0 & 0 & 0 & 0 & 0 & 100 & 79 & 0 & & & \\
\hline 5000 & 0 & 0 & 0 & 0 & 0 & 0 & 96 & 35 & 0 & & & \\
\hline 2500 & 0 & 0 & 0 & 0 & 0 & 0 & 74 & 0 & 0 & 16th $\mathrm{h}$ & 24 th h & 48th $\mathrm{h}$ \\
\hline 1250 & 0 & 0 & 0 & 0 & 0 & 0 & 61 & 0 & 0 & \multicolumn{3}{|c|}{$800 \mu \mathrm{g} / \mathrm{mL}$} \\
\hline 625 & 0 & 0 & 0 & 0 & 0 & 0 & 33 & 0 & 0 & 0 & 75 & 100 \\
\hline 312.5 & 0 & 0 & 0 & 0 & 0 & 0 & 0 & 0 & 0 & 0 & 59 & 100 \\
\hline 156.25 & 0 & 0 & 0 & 0 & 0 & 0 & 0 & 0 & 0 & 0 & 43 & 100 \\
\hline 78.125 & 0 & 0 & 0 & 0 & 0 & 0 & 0 & 0 & 0 & 0 & 25 & 100 \\
\hline 39.062 & 0 & 0 & 0 & 0 & 0 & 0 & 0 & 0 & 0 & 0 & 10 & 100 \\
\hline 19.531 & 0 & 0 & 0 & 0 & 0 & 0 & 0 & 0 & 0 & 0 & 0 & 97 \\
\hline 9.7656 & 0 & 0 & 0 & 0 & 0 & 0 & 0 & 0 & 0 & 0 & 0 & 83 \\
\hline 4.8828 & 0 & 0 & 0 & 0 & 0 & 0 & 0 & 0 & 0 & 0 & 0 & 67 \\
\hline 2.4414 & 0 & 0 & 0 & 0 & 0 & 0 & 0 & 0 & 0 & 0 & 0 & 57 \\
\hline 1.2207 & 0 & 0 & 0 & 0 & 0 & 0 & 0 & 0 & 0 & 0 & 0 & 48 \\
\hline 0.6103 & 0 & 0 & 0 & 0 & 0 & 0 & 0 & 0 & 0 & 0 & 0 & 0 \\
\hline 0.3051 & 0 & 0 & 0 & 0 & 0 & 0 & 0 & 0 & 0 & 0 & 0 & 0 \\
\hline
\end{tabular}




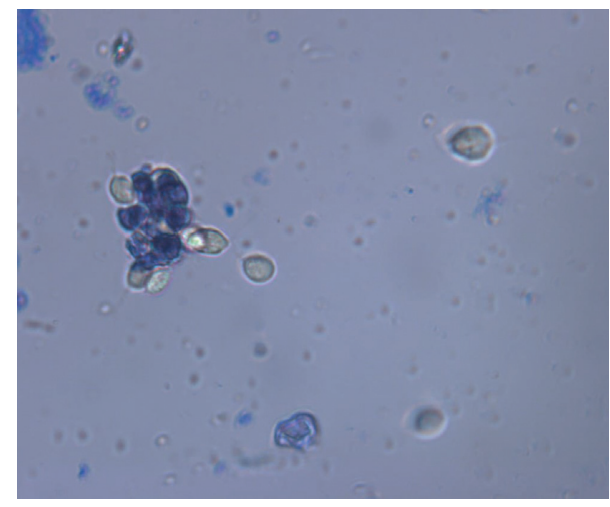

Figure 7: Microscopic image of the trichomonacidal activity of dye I against $T$. vaginalis trophozoites after 48 hours.

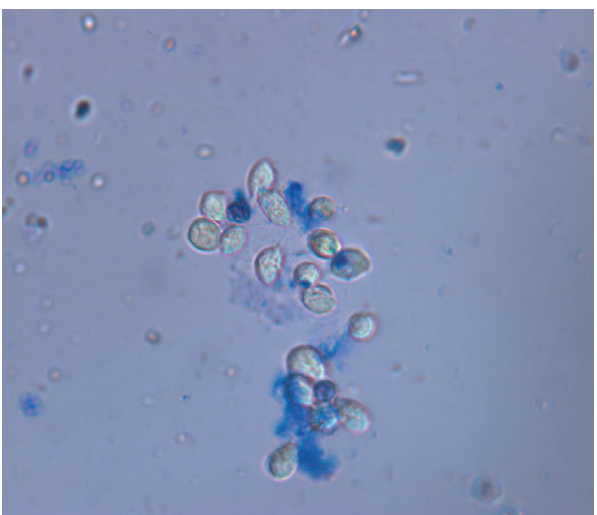

FIGURE 8: Microscopic image of the trichomonacidal activity of dye II against $T$. vaginalis trophozoites after 48 hours.

showed $96 \%, 74 \%, 61 \%$, and $33 \%$ lethal effects at 5000,2500 , 1250 , and $625 \mu \mathrm{g} / \mathrm{mL}$ dilutions, respectively.

\section{Conclusion}

In this study, for the first time, molecular modeling and antiparasitic activity studies were carried out on 6-amino-5[(4-nitrophenyl) diazenyl] pyrimidine-2,4 $(1 \mathrm{H}, 3 \mathrm{H})$-dione (dye I) and 6-amino-5-[(4-bromophenyl) diazenyl] pyrimidin-2,4 $(1 \mathrm{H}, 3 \mathrm{H})$-dione (dye II) given in the literature, which were resynthesized by the same method and whose molecular structures were confirmed using FTIR, ${ }^{1} \mathrm{H}-\mathrm{NMR}$ spectroscopic methods. In molecular modeling study, the molecular structures of the possible tautomeric forms of dyes I and II in the gas state and in DMSO solvent were optimized using the DFT/B3LYP/6-311++G(d,p) method, and their molecular total energies, optimized structures, IR, and ${ }^{1} \mathrm{H}$ NMR spectral data were obtained. IR vibration frequencies were calculated in gas state, and ${ }^{1} \mathrm{H}-\mathrm{NMR}$ chemical shift values were calculated in DMSO solvent. Theoretical spectral data of the possible tautomeric forms of dyes were compared with experimental data obtained from FTIR and ${ }^{1} \mathrm{H}-\mathrm{NMR}$ spectra of dyes. The results show that, for both dyes, the spectral data of the imine-diketo-hydrazone form, which has the lowest energy and hence is determined as the most stable tautomeric form, are consistent with the experimental ones. The optimized structures of dyes in imine-diketo-hydrazone form were obtained in the most stable form that reveals $\mathrm{N}-\mathrm{H}$... O type intramolecular bonds. Therefore, the relevant IR and ${ }^{1} \mathrm{H}$-NMR spectral data are compatible with the experimental ones. However, significant deviations from experimental values observed in IR and ${ }^{1} \mathrm{H}-\mathrm{NMR}$ spectral data of dyes I and II in imine-diketo-hydrazone forms indicate the presence of $\mathrm{N}-\mathrm{H} \cdots \mathrm{O}$ type strong intermolecular hydrogen bonds in the molecular structure of the dyes.

Antiparasitic activities of the dyes were tested as in vitro against $L$. infantum, $L$. major, $L$. tropica promastigotes, and T. vaginalis trophozoites by microdilution broth assay. Antileishmanial and trichomonacidal activities were evaluated considering MIC and MLC values, respectively. Antileishmanial activities of dyes were evaluated by comparing the MIC values obtained in the tests with those obtained for the standard control drug amphotericin B. Results show that dye I has no antileishmanial activity at the concentrations studied against Leishmania species tested, and dye II is effective against L. major promastigotes, but not against other Leishmania species studied. If higher concentrations are studied, the dyes may be found to be effective as antiparasitic. In the trichomonacidal activity study, as a standard control drug, metronidazole was used. According to the data obtained, dyes I and II have trichomonacidal activity at some concentrations studied. In tests, it is determined that azo dyes containing uracil show a lethal effect of $33 \%$ to $100 \%$ and also that dyes tested against $T$. vaginalis trophozoites show a dosedependent effect in vitro.

As a result, the antiparasitic activity results obtained in the study are promising, and due to in vitro antileishmanial and trichomonacidal activities, azo dyes containing uracil may be considered in pharmacological research, and thus the diversity of compounds used may increase. In order for dyes I and II to be good drug candidates, in vivo control studies and toxicity tests should be performed in experimental animal models.

\section{Data Availability}

The data used to support the findings of this study are available from the corresponding author upon request.

\section{Disclosure}

The numerical calculations reported in this paper were fully performed at TUBITAK ULAKBIM, High Performance and Grid Computing Center (TRUBA resources). An oral presentation of a part of this article is available (Turkish Physical Society 35th International Physics Congress, Bodrum $\mathrm{Mu}$ nicipality-Heredot Culture Center, Konacık-Bodrum/Turkey, September 4-8, 2019). This article is prepared from Pınar Kubaşık's master's thesis (Graduate School of Natural and Applied Sciences, Advanced Technologies, Gazi University, Turkey).

\section{Conflicts of Interest}

The authors declare no conflicts of interest. 


\section{Acknowledgments}

The authors would like to thank Dr. Ülkü KARAMAN and Dr. Hatice ERTABAKLAR for their contribution to the antiparasitic activity studies and Dr. Fatih Eyduran for chemical synthesis. This study was supported by Gazi University, Scientific Research Projects Coordination Department (Gazi/BAP) (Project no. 65/2019-03).

\section{References}

[1] A. Mohammadi, B. Khalili, and M. Tahavor, "Novel push-pull heterocyclic azo disperse dyes containing piperazine moiety: synthesis, spectral properties, antioxidant activity and dyeing performance on polyester fibers," Spectrochimica Acta Part A: Molecular and Biomolecular Spectroscopy, vol. 150, pp. 799805, 2015.

[2] M. A. Gouda, H. F. Eldien, M. M. Girges, M. A. Berghot, and M. A. Berghot, "Synthesis and antitumor evaluation of thiophene based azo dyes incorporating pyrazolone moiety," Journal of Saudi Chemical Society, vol. 20, no. 2, pp. 151-157, 2016.

[3] H. Wamhoff, J. Dzenis, and K. Hirota, "Uracils: versatile starting materials in heterocyclic synthesis," Advances in Heterocyclic Chemistry, vol. 55, pp. 129-259, 1992.

[4] B. Kirkan and R. Gup, "Synthesis of new azo dyes and copper (II) complexes derived from barbituric acid and 4-aminobenzoylhydrazone," Turkish Journal of Chemistry, vol. 32, pp. 9-17, 2008.

[5] Z. Seferoğlu, "Study on tautomericequilibria of new hetarylazo-6-aminouracils," Arkivoc, vol. 8, pp. 42-57, 2009.

[6] R. H. Garrett and C. M. Grisham, Principals of Biochemistry with a Human Focus, Cengage Learning Inc., Boston, MA, USA, 1997.

[7] M. Alcolea Palafox, G. Tardajos, A. Guerrero-Martínez et al., "FT-IR, FT-Raman spectra, density functional computations of the vibrational spectra and molecular geometry of biomolecule 5-aminouracil," Chemical Physics, vol. 340, no. 1-3, pp. 17-31, 2007.

[8] S. Dutta Soni, T. Srikrishnant, and J. L. Alderfer, "Halogenated nucleic acids: structure and conformational studies of 5fluorocytidine by X-ray crystallography and nmr spectroscopy," Nucleosides and Nucleotides, vol. 15, no. 11-12, pp. 1945-1957, 1996.

[9] P. Cattand, P. Desjeux, M. G. Guzman et al., Tropical Disease Lacking Adequate Control Measures: Dengue, Leishmaniasis, and African Trypanosomiasis, Disease Control Priorities in Developing Countries, World Bank and Oxford University Press, Washington, DC, USA, 2006.

[10] N. Süleymanoğlu, R. Ustabaş, Ş. Direkel, Y. B. Alpaslan, and Y. Ünver, "1,2,4-triazole derivatives with morpholine; DFT study and antileishmanial activity," Canadian Journal of Physics, vol. 96, no. 7, pp. 719-723, 2018.

[11] B. L. Herwaldt, "Leishmaniasis," The Lancet, vol. 354, no. 9185, pp. 1191-1199, 1999.

[12] S. Belazzoug, "Leishmaniasis in mediterranean countries," Veterinary Parasitology, vol. 44, no. 1-2, pp. 15-19, 1992.

[13] World Health Organization, Leishmaniasis: Overwiev, WHO, Geneva, Switzerland, 2020, https://www.who.int/healthtopics/leishmaniasis\#tab=tab_1.

[14] S. Burza, S. L. Croft, and M. Boelaert, "Leishmaniasis," The Lancet, vol. 392, no. 10151, pp. 951-970, 2018.

[15] L. Anversa, M. G. S. Tiburcio, V. B. Richini-Pereira, and L. E. Ramirez, "Human leishmaniasis in Brazil: a general review," Revista da Associação Médica Brasileira, vol. 64, no. 3, pp. 281-289, 2018.

[16] N. Süleymanoğlu, R. Ustabaş, Y. Ünver, Y. B. Alpaslan, Ş. Direkel, and Ü. Karaman, "5-Phenyl thiophene amino phenol derivatives: synthesis, spectroscopic characterization, computational study and antimicrobial activity," Journal of Molecular Structure, vol. 1182, pp. 36-46, 2019.

[17] R. Ustabaş, N. Süleymanoğlu, Y. Ünver, and Ş. Direkel, "5-(4-Bromobenzyl)-4-(4-(5-phenyl-1,3,4-oxadiazole-2-yl) phenyl)-2,4-dihydro-3H-1,2,4-triazole-3-one: synthesis, characterization, DFT study and antimicrobial activity," Journal of Molecular Structure, vol. 1214, p. 128217, 2020.

[18] J. R. Schwebke and D. Burgess, "Trichomoniasis," Clinical Microbiology Reviews, vol. 17, no. 4, pp. 794-803, 2004.

[19] T. Edwards, P. Burke, H. Smalley, and G. Hobbs, "Trichomonas vaginalis: clinical relevance, pathogenicity and diagnosis," Critical Reviews in Microbiology, vol. 42, no. 3, pp. 406-417, 2016.

[20] S. L. Cudmore, K. L. Delgaty, S. F. Hayward-McClelland, D. P. Petrin, and G. E. Garber, "Treatment of infections caused by metronidazole-resistant Trichomonas vaginalis," Clinical Microbiology Reviews, vol. 17, no. 4, pp. 783-793, 2004.

[21] M. R. Yazdanbakhsh, M. Abbasnia, M. Sheykhan, and L. Ma'mani, "Synthesis, characterization and application of new azo dyes derived from uracil for polyester fibre dyeing," Journal of Molecular Structure, vol. 977, no. 1-3, pp. 266-273, 2010.

[22] Z. Seferoğlu and N. Ertan, "Synthesis, characterization and spectroscopic properties of some new phenylazo-6-aminouracil," Central European Journal of Chemistry, vol. 6, pp. 81-88, 2008.

[23] M. J. Frisch, G. V. Trucks, H. B. Schlegel, G. E. Scuseria, and M. A. Robb, GAUSSIAN 09, Revision C.01, Gaussian, Inc., Wallingford, CT, USA, 2009.

[24] C. Peng, P. Y. Ayala, H. B. Schlegel, and M. J. Frisch, "Using redundant internal coordinates to optimize equilibrium geometries and transition states," Journal of Computational Chemistry, vol. 17, no. 1, pp. 49-56, 1996.

[25] P. J. Stephens, F. J. Devlin, C. F. Chabalowski, and M. J. Frisch, "Ab initio calculation of vibrational absorption and circular dichroism spectra using density functional force fields," The Journal of Physical Chemistry, vol. 98, no. 45, pp. 1162311627, 1994.

[26] R. Dennington, T. Keith, and J. Millam, GAUSSVIEW, Version 5, Semichem Inc., Shawnee Mission, KS, USA, 2009.

[27] A. Abbas, H. Gökce, S. Bahçeli, and M. M. Naseer, "Spectroscopic (FT-IR, Raman, NMR and UV-vis.) and quantum chemical investigations of (E)-3-[4-(pentyloxy)phenyl]-1phenylprop-2-en-1-one," Journal of Molecular Structure, vol. 1075, pp. 352-364, 2014.

[28] H. Gökce, N. Öztürk, M. Taşan, Y. B. Alpaslan, and G. Alpaslan, "Spectroscopic characterization and quantum chemical computations of the 5-(4-pyridyl)-1H-1,2,4-triazole-3-thiol molecule," Spectroscopy Letters, vol. 49, no. 3, pp. 167-179, 2016.

[29] R. Ditchfield, "Molecular orbital theory of magnetic shielding and magnetic susceptibility," The Journal of Chemical Physics, vol. 56, no. 11, pp. 5688-5691, 1972.

[30] K. Wolinski, J. F. Hinton, and P. Pulay, "Efficient implementation of the gauge-independent atomic orbital method for NMR chemical shift calculations," Journal of the American Chemical Society, vol. 112, no. 23, pp. 8251-8260, 1990.

[31] N. Süleymanoğlu, E. E. Demir, Ş. Direkel, and Y. Ünver, "Theoretical study and antimicrobial activities of New Schiff 
base derivatives with thiophene," Journal of Molecular Structure, vol. 1218, Article ID 128522, 2020.

[32] N. O. Iskeleli, Y. B. Alpaslan, Ş. Direkel, A. G. Ertürk, N. Süleymanoğlu, and R. Ustabaş, "The new Schiff base 4-[(4Hydroxy-3-fluoro-5-methoxy-benzylidene)amino]-1,5-dimeth y1-2-phenyl-1,2-dihydro-pyrazol-3-one: experimental, DFT calculational studies and in vitro antimicrobial activity," Spectrochimica Acta Part A: Molecular and Biomolecular Spectroscopy, vol. 139, pp. 356-366, 2015.

[33] M. A. S. Abdelwahid, T. Elsaman, M. S. Mohamed, S. A. Latif, M. M. Mukhtar, and M. A. Mohamed, "Synthesis, characterization, and antileishmanial activity of certain quinoline-4carboxylic acids," Journal of Chemistry, vol. 2019, Article ID 2859637, 9 pages, 2019.

[34] E. V. Costa, H. P. Brígido, J. V. Silva, M. R. Coelho-Ferreira, G. C. Brandão, and M. F. Dolabela, "Antileishmanial activity of Handroanthus serratifolius (Vahl) S. Grose (bignoniaceae)," Evidence-based Complementary and Alternative Medicine, vol. 2017, Article ID 8074275, 6 pages, 2017.

[35] N. Süleymanoğlu, Y. Ünver, R. Ustabaş, Ş. Direkel, and G. Alpaslan, "Antileishmanial activity study and theoretical calculations for 4-amino-1,2,4-triazole derivatives," Journal of Molecular Structure, vol. 1144, pp. 80-86, 2017.

[36] N. Süleymanoğlu, R. Ustabaş, Ş. Direkel, Y. B. Alpaslan, and Y. Ünver, "1,2,4-triazole derivative with Schiff base; thiolthione tautomerism, DFT study and antileishmanial activity," Journal of Molecular Structure, vol. 1150, pp. 82-87, 2017.

[37] C. L. C. Brandelli, P. B. Vieira, A. J. Macedo, and T. Tasca, "Remarkable anti-Trichomonas vaginalis activity of plants traditionally used by the Mbyá-Guarani indigenous group in Brazil," BioMed Research International, vol. 2013, Article ID 826370, 7 pages, 2013.

[38] H. Ertabaklar, B. Kivçak, T. Mert, and S. Ozensoy Töz, "In vitro activity of arbutus unedo leaf extracts against Trichomonas vaginalis trophozoites," Turkiye Parazitolojii Dergisi, vol. 33, pp. 263-265, 2009.

[39] R. Bengiat, A. Klein, M. Gil et al., "5-[2,4-Dihydroxy-5-(5hydroxy-2,4,6-trioxo-3,5-dihydro-1H-pyrimidin-5-yl)-3methoxyphenyl]-5-hydroxy-3,5-dihydro-1H-pyrimidine2,4,6-trione pentahydrate," IUCrData, vol. 1, no. 2, Article ID x160261, 2016.

[40] R. Ustabaş, U. Çoruh, K. Sancak, E. Demirkan, and E. M. Vazquez-Lopez, "1-(Acetonyl)-3-(2-thienylmethyl)-4(4H-1, 2, 4-triazol-4-yl)-1H-1, 2, 4-triazol-5 (4H)-one,” Acta Crystallographica Section E: Structure Reports Online, vol. 63, no. 5, pp. o2774-o2775, 2007.

[41] S. Das, B. K. Saikia, B. Sridhar, and A. J. Thakur, "6-[(Dimethylamino)methyleneamino]-1,3-dimethylpyrimidine-2,4(1H,3H)-dione dihydrate," Acta Crystallographica Section E: Structure Reports Online, vol. 64, p. 1662, 2008.

[42] A. R. Kennedy, S. C. McKellar, and M. O. Okoth, "The cobalt(II) salt of the azo dye Orange G," Acta Crystallographica. Section E, Structure Reports Online, vol. 66, pp. m1330-m1331, 2010.

[43] Z. Seferoğlu, T. Hökelek, E. Şahin, and N. Ertan, "6-Amino1,3-dimethyl-5-(4-methylthiazol-2-yldiazenyl) uracil," Acta Crystallographica Section E: Structure Reports Online, vol. 63, pp. 571-573, 2007. 